\title{
Fifteen-year single-center experience with the Norwood operation for complex lesions with single-ventricle physiology compared with hypoplastic left heart syndrome
}

\author{
Jan H. Hansen, MD, ${ }^{\mathrm{a}}$ Colin Petko, MD, ${ }^{\mathrm{a}}$ Gero Bauer, MD, ${ }^{\mathrm{a}}$ Inga Voges, $\mathrm{MD},{ }^{\mathrm{a}}$ \\ Hans-Heiner Kramer, MD, $\mathrm{PhD},{ }^{\mathrm{a}}$ and Jens Scheewe, $\mathrm{MD}^{\mathrm{b}}$
}

\begin{abstract}
Objective: The Norwood procedure, the first surgical step of staged palliation for hypoplastic left heart syndrome, is also applied for other complex single-ventricle lesions with systemic outflow tract obstruction or aortic arch hypoplasia. We reviewed our 15-year institutional experience with the Norwood procedure for patients with and without hypoplastic left heart syndrome.
\end{abstract}

\begin{abstract}
Methods: A total of 41 patients without hypoplastic left heart syndrome and 212 patients with hypoplastic left heart syndrome who underwent a Norwood procedure between January 1996 and December 2010 were enrolled. Full medical records were reviewed to assess the determinants of outcome.

Results: Early failure (death or cardiac transplantation) was 7\% in patients without hypoplastic left heart syndrome and $13 \%$ in patients with hypoplastic left heart syndrome $(P=.29)$. Frequency of postoperative complications, duration of postoperative ventilation, and length of vasoactive drug treatment were not different between groups. Transplant-free survival until the second operative step trended to be higher for patients without hypoplastic left heart syndrome ( $92 \%$ vs $80 \%, P=.067)$. Recurrent aortic arch obstruction was more common in patients without hypoplastic left heart syndrome $(15 / 39$ vs $32 / 171, P=.008)$, but there were 4 patients with stenosis of the proximal aortic arch. In subsequent procedures, 31 patients without hypoplastic left heart syndrome underwent superior cavopulmonary anastomosis and 5 biventricular repair. Overall transplant-free survival was not different between groups $(P=.119)$ but trended to be higher in patients with a systemic or substantial left ventricle remnant contributing to cardiac output $(P=.082)$.

Conclusions: Early and long-term survivals and postoperative complications were similar between patients with and without hypoplastic left heart syndrome undergoing a Norwood operation. Recurrent aortic arch obstruction was common in both groups but more prevalent in patients without hypoplastic left heart syndrome. (J Thorac Cardiovasc Surg 2012;144:166-72)
\end{abstract}

The outcome for patients with hypoplastic left heart syndrome (HLHS) has dramatically improved over the past 2 decades because of refinement of surgical technique and perioperative care. ${ }^{1-4}$ We recently reported our institutional 12-year experience with the Norwood procedure as firststage palliation for HLHS and noted a remarkable reduction of early mortality within the study period. ${ }^{5,6}$

The Norwood procedure is also applied for other complex single-ventricle lesions with severe systemic outflow tract obstruction, including aortic arch hypoplasia (non-HLHS group). Conflicting results concerning the postoperative

From the Department of Congenital Heart Disease and Pediatric Cardiology, ${ }^{\mathrm{a}}$ and the Department of Cardiovascular Surgery, ${ }^{\mathrm{b}}$ University Hospital of SchleswigHolstein, Campus Kiel, Kiel, Germany.

Disclosures: Authors have nothing to disclose with regard to commercial support.

Received for publication Sept 26, 2011; revisions received Nov 21, 2011; accepted for publication Dec 14, 2011; available ahead of print Jan 13, 2012.

Address for reprints: Jan H. Hansen, MD, Department of Congenital Heart Disease and Pediatric Cardiology, University Hospital of Schleswig Holstein, Campus Kiel, Arnold-Heller Strasse 3, House 9, 24105 Kiel, Germany (E-mail: jan. hansen@uk-sh.de).

0022-5223/\$36.00

Copyright (c) 2012 by The American Association for Thoracic Surgery doi:10.1016/j.jtcvs.2011.12.020 and long-term outcome for this heterogeneous group of patients have been reported. ${ }^{7-10}$ We evaluated our 15-year single-center outcome of the Norwood operation for complex single-ventricle lesions in comparison with patients with HLHS.

\section{MATERIALS AND METHODS}

We reviewed our surgical database to identify patients who underwent a modified Norwood procedure between January 1, 1996, and December 31,2010 . Patients with single-ventricle physiology who did not require aortic arch reconstruction were excluded. Follow-up lasted until March 31, 2011. Patients with a functional single ventricle and systemic outflow tract obstruction, including aortic arch hypoplasia not complying with the diagnostic criteria for HLHS, were classified as the non-HLHS group. ${ }^{11}$ For these patients, the dominant systemic ventricle was determined by echocardiography, and the group was subdivided into patients with a right systemic ventricle and patients with a systemic left ventricle. Patients with a dominant right ventricle who had a substantial left ventricle contributing to cardiac output were also assigned to the left ventricle group. Patients with HLHS were assigned to distinct anatomic subgroups (mitral and aortic atresia, mitral atresia and aortic stenosis, mitral stenosis and aortic atresia, and mitral and aortic stenosis) according to the echocardiography performed before the Norwood operation. ${ }^{11}$ Full medical records were reviewed to assess patient, hemodynamic, procedural, and morphologic determinants of outcome. Informed consent for anonymized data analysis had been 


\section{Abbreviations and Acronyms \\ DHCA $=$ deep hypothermic circulatory arrest \\ HLHS $=$ hypoplastic left heart syndrome \\ RVPA $=$ right ventricle to pulmonary artery \\ VSD $=$ ventricular septal defect}

obtained for every patient, and local ethics committee approval was waived because of the retrospective nature of the study.

\section{Preoperative Treatment}

All patients were treated according to a standardized preoperative treatment protocol with low-dose prostaglandin E1, afterload reduction with sodium-nitroprusside or phentolamine. and avoidance of mechanical ventilation or inotropic support. ${ }^{5}$

\section{Norwood Operation}

In our routine Norwood procedure, the pulmonary artery is transected at the bifurcation. The arterial duct is ligated and divided, and ductal tissue is completely excised from the aortic wall. Potential coarctation is resected. The descending aorta is incised for approximately $5 \mathrm{~mm}$, and the incision is elongated longitudinally along the inner curvature deep into the aortic root, which results in a short pre-coronary segment. The proximal end of the pulmonary trunk is connected side-by-side with the diminutive ascending aorta. The aortic arch and ascending aorta are patch augmented and connected with the circumference of the transected pulmonary artery to construct the neoaorta. From 1996 to 1999, the aortic arch was augmented with pulmonary homograft (non-HLHS, $\mathrm{n}=9$; HLHS, $\mathrm{n}=32$ ). Since 2000 , bovine pericardium has been used.

The Norwood procedure was slightly modified in some of the patients in the non-HLHS group. Depending on the underlying anatomy and the size of the native ascending aorta, the longitudinal incision along the aorta was extended only up to the level of the transected pulmonary trunk, and then both vessels were connected side by side. In the presence of transposed great arteries, the longitudinal incision along the inner curvature of the aortic arch was extended to the dorsal aspect of the ascending aorta. The ventral side of the pulmonary trunk facing the ascending aorta was incised in a v-shaped fashion and connected side by side with the native ascending aorta.

A modified Blalock-Taussig shunt between the distal part of the innominate artery and the patch-reconstructed pulmonary bifurcation provided pulmonary blood flow in our standard Norwood procedure for the HLHS and non-HLHS groups. A central aortopulmonary shunt was routinely used in the presence of an aberrant right subclavian artery. Since 2004, a right ventricle to pulmonary artery (RVPA) shunt was occasionally placed in patients with low weight or in patients in the non-HLHS group with a hypoplastic residual outlet chamber connected to the systemic ventricle by an unrestrictive ventricular septal defect (VSD). Repair of associated defects was performed as necessary. Selective cerebral perfusion during aortic arch reconstruction was initiated in 2000 and has been used in all patients since then. Routine primary chest closure was intended in all patients. Delayed sternal closure was only performed in hemodynamically unstable patients.

Subsequent operative steps for the non-HLHS and HLHS groups included a superior cavopulmonary anastomosis using the hemi-Fontan technique described by Bove, ${ }^{12}$ followed by a fenestrated Fontan operation with an intra-atrial tunnel.

\section{Postoperative Management}

Our routine postoperative management has been described. ${ }^{5,6}$ Postoperative inotropic support was achieved with epinephrine and afterload reduction with sodium-nitroprusside or phentolamine. Beginning in March 2010, epinephrine and milrinone were the only routinely used vasoactive agents. The postoperative course was evaluated for the occurrence of complications and the duration of mechanical ventilation and vasoactive drug therapy.

\section{Outcome Measures}

Early failure after the Norwood operation was defined as death or cardiac transplantation during the first 30 postoperative days or before discharge from the hospital. Death or cardiac transplantation in discharged patients occurring more than 30 days after the Norwood procedure and before the second surgical step was referred to as interstage failure. Postoperative complications were classified as cardiac complications (cardiopulmonary resuscitation, arrhythmias, and shunt dysfunction) and noncardiac complications (sepsis and neurologic complications, eg, seizures, cerebral hemorrhage, and cerebral infarct)..$^{5}$ The frequency of recurrent aortic arch obstruction and the need for balloon angioplasty or surgical reintervention between the Norwood procedure and the second surgical step were evaluated by reviewing cardiac catheterization reports. Recurrent aortic arch obstruction was defined as a pressure gradient exceeding $20 \mathrm{~mm} \mathrm{Hg}$ or a localized narrowing regardless of the gradient. Systemic atrioventricular valve regurgitation was assessed on the day before the second surgical step and quantified using color Doppler techniques. The degree of regurgitation was graded subjectively as absent, mild, mild to moderate, moderate to severe, or severe.

\section{Statistics}

Statistical analyses were performed with the Statistical Package for the Social Sciences 17.0 (SPSS Inc, Chicago, Ill). Continuous variables are presented as mean and standard deviation or median and range as appropriate; categoric data are displayed as number and percentages. Continuous variables were analyzed with the Student $t$ test for 2 independent samples after testing for equality of variances of data with the Levene test. Nonparametric data were analyzed with the Mann-Whitney $U$ test. For categoric data, the chi-square or Fisher exact test was applied. In addition, univariate logistic regression analysis was used to evaluate continuous variables as risk factors for early failure after the Norwood operation. For multivariate analyses, variables with a $P$ value of .1 or less on univariate analysis were entered into a stepwise logistic regression model. Survival was calculated with the Kaplan-Meier method and compared using the Breslow test.

\section{RESULTS \\ Patient Characteristics}

Overall, 41 patients (29 male, 12 female) in the nonHLHS group and 212 patients (132 male, 80 female) in the HLHS group were enrolled. Cardiac diagnoses of the non-HLHS group are shown in Table 1. In the non-HLHS group, 26 patients $(63 \%)$ had a systemic left ventricle or a substantial left ventricle remnant contributing to cardiac output. The non-HLHS group included 3 patients in whom an initial biventricular attempt failed (critical aortic stenosis $\mathrm{n}=2$, mitral valve hypoplasia $\mathrm{n}=1$ ). One patient received serial stenting of the hypoplastic aortic arch at an outside hospital.

In the HLHS group, mitral and aortic atresia were observed in 99 patients $(47 \%)$, mitral and aortic stenosis were observed in 50 patients $(24 \%)$, mitral stenosis and aortic atresia were observed in 50 patients $(24 \%)$, and mitral atresia and aortic stenosis were observed in 13 patients $(6 \%)$. 
TABLE 1. Cardiac anatomy in the non-hypoplastic left heart syndrome group $(n=41)$

\begin{tabular}{|c|c|c|}
\hline \multicolumn{3}{|l|}{ Cases with a systemic right ventricle $(\mathrm{n}=15)$} \\
\hline Unbalanced atrio-VSD & 6 & $(14.6 \%$ \\
\hline Mitral atresia or severe mitral stenosis & 5 & $(12.2 \%$ \\
\hline Double-outlet right ventricle & 3 & $(9.8 \%)$ \\
\hline Critical aortic stenosis with aortic arch hypoplasia & 1 & $(2.4 \%)$ \\
\hline \multicolumn{3}{|l|}{$\begin{array}{l}\text { Cases with a systemic left or substantial left ventricle } \\
\text { remnant }(\mathrm{n}=26)\end{array}$} \\
\hline $\begin{array}{l}\text { Double-inlet left ventricle with transposition of the } \\
\text { great arteries }\end{array}$ & 7 & $\left(17.1^{\circ}\right.$ \\
\hline $\begin{array}{l}\text { Tricuspid atresia with transposition of the great } \\
\text { arteries }\end{array}$ & 4 & $(9.8 \%)$ \\
\hline ccTGA with tricuspid valve atresia/stenosis & 2 & $(4.9 \%)$ \\
\hline $\begin{array}{l}\text { Criss-cross heart with transposition of the great } \\
\text { arteries }\end{array}$ & 1 & $(2.4 \%)$ \\
\hline Transposition of the great arteries with aortic atresia & 1 & $(2.4 \%)$ \\
\hline $\begin{array}{l}\text { Transposition of the great arteries with interrupted } \\
\text { aortic arch }\end{array}$ & 1 & $(2.4 \%)$ \\
\hline Aortic atresia with VSD & 8 & $(19.5 \%$ \\
\hline Double-outlet right ventricle & 1 & $(2.4 \%)$ \\
\hline Critical aortic stenosis with aortic arch hypoplasia & 1 & $(2.4 \%)$ \\
\hline
\end{tabular}

$V S D$, Ventricular septal defect; $c c T G A$, congenitally corrected transposition of the great arteries.

The native ascending aorta was significantly smaller in the HLHS group $(3.4 \pm 1.4 \mathrm{~mm}$ vs $4.9 \pm 2.1 \mathrm{~mm}$, $P<.001)$. The ascending aorta diameter was $2 \mathrm{~mm}$ or less in 8 patients $(20 \%)$ in the non-HLHS group and in 44 patients $(21 \%)$ in the HLHS group $(P=.86)$.

An aberrant right subclavian artery was found in 3 patients $(7 \%)$ in the non-HLHS group and in 15 patients $(7 \%)$ in the HLHS group. Total anomalous pulmonary venous return was diagnosed in 1 patient in the non-HLHS group and in 4 patients in the HLHS group. Four additional patients with HLHS had partial anomalous pulmonary venous return.

An accompanying genetic syndrome was seen in 2 patients $(5 \%)$ in the non-HLHS group and 5 patients $(2 \%)$ in the HLHS group. Prematurity accounted for 3 patients $(7 \%)$ in the non-HLHS group and 14 patients $(7 \%)$ in the HLHS group. Preoperative complications included necrotizing enterocolitis (non-HLHS: $\mathrm{n}=5,12 \%$; HLHS: $\mathrm{n}=10,5 \%)$ and cardiac decompensation with signs of multiorgan failure (non-HLHS: $\mathrm{n}=1,2 \%$; HLHS: $\mathrm{n}=24$, $11 \%$ ) requiring resuscitation in 1 patient in the nonHLHS group and 5 patients in the HLHS group.

\section{Norwood Procedure}

Table 2 shows data of the Norwood procedure and variables of the postoperative course compared between the non-HLHS and HLHS groups. No differences in weight and age at operation existed.

An RVPA shunt was more frequently used in the nonHLHS group (non-HLHS: $\mathrm{n}=6,15 \%$ vs HLHS: $\mathrm{n}=2$, $1 \% P<.001)$. In the beginning of the study period, 12 patients $(29 \%)$ in the non-HLHS group and 40 patients $(19 \%)$ in the HLHS group underwent operation with deep hypothermic circulatory arrest (DHCA) with a mean duration of $76 \pm 15$ minutes and $71 \pm 16$ minutes, respectively $(P=.36)$. Overall, the duration of cardiopulmonary bypass, aortic crossclamp, DHCA, and total support time was not different between the non-HLHS and HLHS groups, but myocardial ischemia was longer in the non-HLHS group ( $65 \pm 19$ minutes vs $56 \pm 19$ minutes, $P=.005$ ).

\section{Postoperative Course}

Duration of postoperative mechanical ventilation, inotropic support, and afterload reduction was not different between the non-HLHS and HLHS groups (Table 2). Postoperative complications were seen in 21 patients $(51 \%)$ in the non-HLHS group and 106 patients $(50 \%)$ in the HLHS group $(P=.89)$. Cardiopulmonary resuscitation accounted for $6(35 \%)$ and $39(46 \%)$ of the cardiac complications in the non-HLHS and HLHS groups, respectively $(P=.40)$.

\section{Outcome After Norwood Operation}

Early failure after the Norwood procedure was $12 \%$ for the entire cohort, $7 \%$ for the non-HLHS group ( 3 early deaths), and $13 \%$ for the HLHS group (27 early deaths, 1 cardiac transplantation) $(P=.29)$. The results of univariate risk factor analysis are shown in Table 3. In a stepwise multivariate model, only longer duration of myocardial ischemia was associated with a higher risk for early failure (odds ratio, 1.47; confidence interval, 1.11-1.94) per 15minute increase $(P=.007)$.

Interstage failure did not occur in the non-HLHS group but did occur in 15 patients $(8 \%)$ in the HLHS group $(P=.14)$. Overall, transplant-free survival until the second operative step was $92 \%$ for the non-HLHS group and $80 \%$ for the HLHS group $(P=.067)$.

\section{Recurrent Aortic Arch Obstruction}

Between the Norwood operation and the subsequent second operative step, 39 patients in the non-HLHS group and 171 patients in the HLHS group underwent cardiac catheterization. Recurrent aortic arch obstruction was noted in 15 patients $(38 \%)$ in the non-HLHS group and was significantly more common compared with the HLHS group, with 32 cases $(19 \%)(P=.008)$. Although aortic arch obstruction in the HLHS group occurred in the aortic isthmus region only, stenosis of the neoascending aorta or proximal aortic arch developed in 4 patients in the non-HLHS group. The patch material was not associated with an increased risk for recurrent obstruction (pulmonary homograft: 6/35 vs bovine pericardium: $41 / 175 ; P=.42$ ). In the non-HLHS group, recurrent obstruction in cases with transposition of the great arteries tended to be less common compared with the remainder $(4 / 18$ vs $11 / 21, P=.054)$ and included stenosis of the proximal aortic arch in 1 case only. 
TABLE 2. Norwood procedure and postoperative course

\begin{tabular}{|c|c|c|c|c|c|}
\hline \multirow[b]{2}{*}{ Norwood procedure } & \multicolumn{2}{|c|}{ non-HLHS $(n=41)$} & \multicolumn{2}{|c|}{ HLHS $(n=212)$} & \multirow[t]{2}{*}{$P$ value } \\
\hline & & & & & \\
\hline Median age (d) & 6 & $(1-125)$ & 6 & $(1-57)$ & .35 \\
\hline Weight $(\mathrm{kg})$ & 3.28 & \pm 0.65 & 3.24 & \pm 0.54 & .73 \\
\hline Weight $\leq 2.5 \mathrm{~kg}(\mathrm{n})$ & 6 & $(15 \%)$ & 23 & $(11 \%)$ & .59 \\
\hline Shunt type & & & & & $<.001$ \\
\hline Modified BT shunt & 32 & $(78 \%)$ & 199 & $(94 \%)$ & \\
\hline Central shunt & 3 & $(7 \%)$ & 11 & $(5 \%)$ & \\
\hline RVPA shunt & 6 & $(15 \%)$ & 2 & $(1 \%)$ & \\
\hline Indexed BT shunt diameter $(\mathrm{mm} / \mathrm{kg})$ & 1.06 & \pm 0.17 & 1.05 & \pm 0.13 & .72 \\
\hline Selective antegrade cerebral perfusion (n) & 29 & $(71 \%)$ & 172 & $(81 \%)$ & .13 \\
\hline Cardiopulmonary bypass $(\mathrm{min})$ & 143 & \pm 51 & 136 & \pm 40 & .30 \\
\hline Aortic crossclamp (min) & 42 & \pm 31 & 39 & \pm 21 & .50 \\
\hline $\mathrm{DHCA}(\mathrm{min})$ & 23 & \pm 34 & 17 & \pm 28 & .32 \\
\hline Myocardial ischemia (min) & 65 & \pm 19 & 56 & \pm 19 & .005 \\
\hline Total support time (min) & 166 & \pm 49 & 152 & \pm 30 & .10 \\
\hline Delayed sternal closure (n) & 9 & $(22 \%)$ & 24 & $(11 \%)$ & .064 \\
\hline \multicolumn{6}{|l|}{ Postoperative course } \\
\hline Ventilation (h) & 67 & $(27-528)$ & 71 & $(15-1191)$ & .36 \\
\hline Inotropic support (h) & 47 & $(13-240)$ & 48 & $(4-575)$ & .87 \\
\hline Afterload reduction $(\mathrm{h})$ & 72 & $(24-213)$ & 72 & $(4-696)$ & .78 \\
\hline Cardiac complications (n) & 17 & $(42 \%)$ & 84 & $(37 \%)$ & .82 \\
\hline Noncardiac complications (n) & 7 & $(17 \%)$ & 41 & $(19 \%)$ & .74 \\
\hline \multicolumn{6}{|l|}{ Second-stage procedure } \\
\hline Hemifontan (n) & 31 & $(76 \%)$ & 168 & $(79 \%)$ & \\
\hline Biventricular repair (n) & 5 & $(12 \%)$ & NA & & \\
\hline More than moderate systemic AVVR (n) & 2 & $(6 \%)$ & 19 & $(11 \%)$ & .38 \\
\hline Median age second-step procedure (mo) & 5.0 & $(1.3-34.5)$ & 4.0 & $(1.1-45.1)$ & .001 \\
\hline
\end{tabular}

$\overline{H L H S}$, Hypoplastic left heart syndrome; $N A$, not applicable; $R V P A$, right ventricle to pulmonary artery; $D H C A$, deep hypothermic circulatory arrest; $A V V R$, atrioventricular valve regurgitation; $B T$, Blalock-Taussig.

With the exception of 2 patients in each group, who were referred to reoperation, all patients underwent balloon angioplasty. Restenosis after balloon angioplasty occurred in 4 patients of the non-HLHS group, which was addressed by repeat balloon angioplasty first. However, 2 patients underwent aortic arch reconstruction during the second operative step because of a residual gradient. In the HLHS

TABLE 3. Univariate risk factor analysis for early mortality after the Norwood procedure

\begin{tabular}{lll}
\hline \multicolumn{1}{c}{ Risk factor } & OR $(\mathbf{9 5} \% \mathbf{C I})$ & $\boldsymbol{P}$ value \\
\hline Gender female & $2.05(0.96-4.37)$ & .060 \\
Prematurity & $1.59(0.43-5.89)$ & .45 \\
Non-HLHS & $0.52(0.15-1.79)$ & .29 \\
Systemic right ventricle & $3.81(0.50-29.14)$ & .25 \\
Aberrant right subclavian artery & $3.09(1.02-9.37)$ & .037 \\
Anomalous pulmonary venous return & $3.86(0.91-16.29)$ & .084 \\
Diameter ascending aorta $\leq 2 \mathrm{~mm}$ & $2.04(0.90-4.66)$ & .085 \\
Weight at operation $\leq 2.5 \mathrm{~kg}$ & $2.08(0.77-5.59)$ & .14 \\
Use of DHCA & $2.43(1.08-5.46)$ & .028 \\
Duration of TSPT (per 15-min increase) & $1.18(1.03-1.36)$ & .019 \\
Duration of MI (per 15-min increase) & $1.47(1.11-1.94)$ & .007 \\
\hline
\end{tabular}

$O R$, Odds ratio; $C I$, confidence interval; $H L H S$, hypoplastic left heart syndrome; $D H C A$, deep hypothermic circulatory arrest; TSPT, total support time; $M I$, myocardial ischemia. group, restenosis was detected in 3 cases before the hemiFontan operation.

\section{Second-Stage Procedure}

Overall, 204 patients underwent a subsequent secondstage procedure. A hemi-Fontan operation was performed in 31 patients in the non-HLHS group, and biventricular repair with a Rastelli type of operation (VSD closure and placement of RVPA conduit) was achieved in 4 patients with aortic atresia and VSD and in 1 patient with a double-outlet right ventricle. Two of the remaining 4 patients with aortic atresia had VSDs that were not suitable for a Rastelli operation because of their location. In the 2 other cases, borderline left ventricular size was the reason for a univentricular approach. All remaining 3 cases with double-outlet right ventricle had severe left ventricular hypoplasia prohibiting biventricular repair. Both patients with transposition of the great arteries had a hypoplastic, non-apex-forming right ventricle, and a biventricular approach was not possible.

At the end of follow-up, 168 patients in the HLHS group had undergone a hemi-Fontan operation. Age at the hemiFontan operation was $4.7(1.3-16.7)$ months in the nonHLHS group and $4.0(1.1-45.1)$ months in the HLHS group 

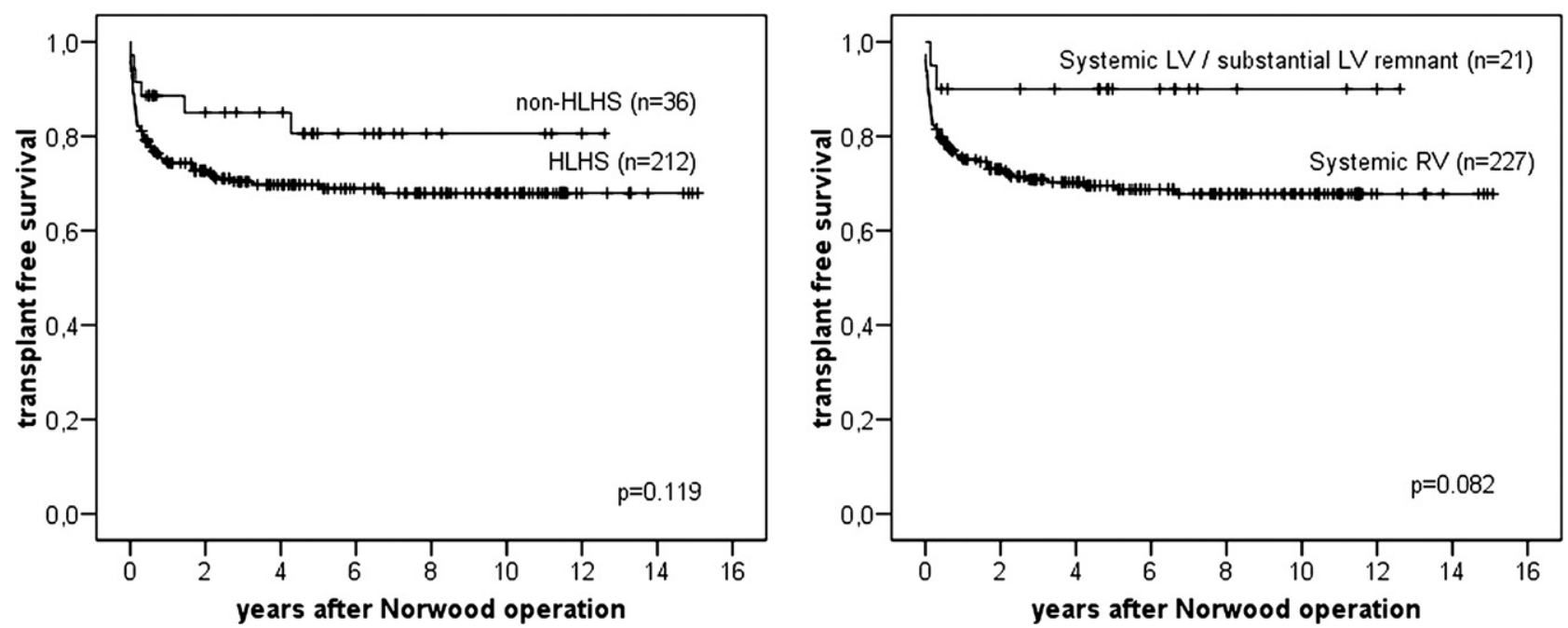

FIGURE 1. Kaplan-Meier estimated transplant-free survival after the Norwood operation compared between the non-HLHS and HLHS groups and between patients with a systemic right ventricle and patients with a systemic left ventricle or substantial left ventricle remnant. $L V$, Left ventricle; $H L H S$, hypoplastic left heart syndrome; $R V$, right ventricle.

$(P=.022)$. The patients who had biventricular repair underwent operation at a median age of $21.2(5.8-34.5)$ months. Early death after the second-stage procedure occurred in 2 patients in the non-HLHS group and 7 patients in the HLHS group $(P=.66)$.

\section{Survival Analysis}

Follow-up after the Norwood procedure was complete for all but 1 of the 186 surviving patients with a median of 6.2 (0.3-15.1) years. In the non-HLHS group, 1 patient was waiting for a hemi-Fontan operation and 1 patient was lost to follow-up. In the HLHS group, 1 patient received a heart transplant after the Norwood operation and 2 patients received a heart transplant after the hemi-Fontan procedure. One patient was not suitable for the creation of a Fontan pathway and underwent multiple shunt replacements. Interstage death between the hemi-Fontan operation and the Fontan completion occurred in 8 patients in the HLHS group. Until the end of follow-up, 22 patients in the non-HLHS group and 108 patients in the HLHS group had proceeded to completion of the Fontan circulation with no early deaths, but 1 late death in the non-HLHS group and 4 late deaths in the HLHS group. Overall, 50 patients were awaiting Fontan completion. All patients who had biventricular repair were alive at the end of the follow-up period.

The 5 patients who underwent biventricular repair were excluded from analysis of long-term outcome. Transplantfree survival was not statistically different between the HLHS and the non-HLHS groups $(P=.119)$, and trended to be higher in patients with a systemic left or substantial left ventricle remnant contributing to cardiac output $(P=.082)$ (Figure 1).

Transplant-free survival after the second surgical step was not different between the non-HLHS and HLHS groups
$(P=.69)$ and between cases with a morphologic right or left systemic ventricle $(P=.46)$.

\section{DISCUSSION}

Congenital heart defects with single-ventricle physiology and systemic outflow tract obstruction other than HLHS requiring a Norwood operation are relatively rare, and alternative surgical approaches, such as pulmonary artery banding together with aortic arch repair, subaortic resection, or palliative arterial switch operation, have been described. ${ }^{13,14}$ Only $16 \%$ of our patients who underwent a Norwood operation in the last 15 years were classified as "non-HLHS," and the underlying anatomy showed great variability. The main finding of our study was that the Norwood operation can be applied with good short- and long-term results regardless of the underlying anatomy and ventricular morphology.

In our cohort, minor differences in surgical technique existed between the HLHS and non-HLHS groups. Pulmonary blood flow is routinely provided by a Blalock-Taussig shunt. The RVPA shunt is avoided because of potential disadvantages from a ventriculotomy of the systemic right ventricle. In non-HLHS cases with a hypoplastic residual outlet chamber connected to the systemic ventricle by an unrestrictive VSD, an RVPA shunt can be placed without potentially harming the systemic ventricle. This explains the more frequent use in the non-HLHS group.

The construction of the neoaorta can be more complex with transposed great arteries. Different techniques including transection of both vessels, pulmonary artery and ascending aorta, or techniques using 2 patches to avoid a single spiral-shaped patch have been described. ${ }^{8,15,16}$ We prefer a single patch to avoid multiple anastomotic sites. Recurrent aortic arch obstruction in patients with 
transposition of the great arteries tended to be less frequent compared with the remaining patients in the non-HLHS group. However, it is a relatively common problem after the Norwood procedure and affects approximately $20 \%$ of the cases varying on the definition applied. ${ }^{17,18}$ The cause is most likely multifactorial and influenced by the surgical technique, type of patch material, and residual ductal tissue in the distal arch. ${ }^{19}$ In our cohort, recurrent aortic arch obstruction was diagnosed in $19 \%$ of patients in the HLHS group and $38 \%$ of patients in the non-HLHS group. No differences regarding the resection of the ductal tissue existed. In contrast with our patients in the HLHS group who only developed restenosis of the distal aortic arch, stenosis of the neoascending aorta or the proximal aortic arch was detected in 4 patients in the non-HLHS group, which explains the higher incidence of recurrent aortic arch obstruction.

Our study showed that early survival was not different between the non-HLHS and HLHS groups, and that a systemic right ventricle was not associated with a higher risk for early failure. In addition, postoperative outcome parameters, such as frequency of postoperative complications, duration of mechanical ventilation, and length of vasoactive drug therapy, were not different between the non-HLHS and HLHS groups. Several previous studies evaluated the outcome after the Norwood procedure for complex single-ventricle lesions. Jacobs and colleauges ${ }^{8}$ compared their single-center experience with the Norwood operation between children with HLHS and patients with related malformations; they found that right ventricular dominance was a significant predictor of mortality. Daebritz and colleagues ${ }^{9}$ reported higher operative survival in a group of 63 patients with other lesions than HLHS compared with 131 patients with HLHS. They hypothesized that a morphologic left systemic ventricle was contributing to higher survival in the non-HLHS group. In agreement with our results, 2 other studies did not find a significant difference in operative survival between patients with other forms of single-ventricle physiology and patients with HLHS undergoing the Norwood procedure. 4, $^{4}$ The outcome after the Norwood operation in 37 patients with transposition of the aorta and functional single left ventricle was not different compared with patients with HLHS in a study conducted by Lotto and colleagues. ${ }^{20}$ In addition to the presence of a single right ventricle, various other risk factors for higher hospital mortality after the Norwood procedure have been reported. ${ }^{1-5,16}$ In our cohort, the only patient-related risk factor was the presence of an aberrant right subclavian artery. Prematurity, HLHS or a systemic right ventricle, an ascending aorta diameter of $2 \mathrm{~mm}$ or less, and low weight at operation were not found to increase the risk for early failure after Norwood operation. As procedural risk factors, the use of DHCA and longer duration of total support time and myocardial ischemia were associated with a higher risk for early death.
Interstage mortality after the Norwood operation is still a concern and occurred in 15 patients of the HLHS group but was not present in the non-HLHS group. As a consequence, survival up to superior cavopulmonary anastomosis trended to be lower in the HLHS group. The physiology of the Norwood circulation is the same for those with nonHLHS and HLHS. The volume load for the systemic ventricle is increased because of shunt-dependent pulmonary blood flow. In the non-HLHS group, 63\% had a systemic left ventricle or 2 relatively well-developed ventricles, which might be more capable of coping with the volume overload and the exposure to systemic pressures.

Five patients in the non-HLHS group underwent biventricular repair. A subsequent biventricular repair may be an option for patients who have an adequate mitral valve and left ventricular dimensions at the time of secondstage surgery, usually in the presence of a VSD. Although staged biventricular repair seems to be a relatively safe option for this small subset of patients, early relief of cyanosis, shunt-independent pulmonary blood flow, and reduction of volume load are arguments for primary repair, which can be performed alternatively with low mortality. ${ }^{21,22}$

In our single-center experience, long-term outcome was not different between the non-HLHS and HLHS groups. However, the impact of ventricular morphology on longterm outcome in patients with a single ventricle is an ongoing debate. In our cohort, overall survival in patients with a systemic left ventricle only trended to be higher compared with cases with a right systemic ventricle. This can be attributed to mortality between the Norwood operation and the second operative step. Thereafter, survival was not different. Recent studies evaluating the long-term outcome after the Fontan operation also reported that ventricular morphology has no impact on survival after Fontan completion. ${ }^{23,24}$ These studies also included patients without a prior Norwood operation. All these results are encouraging for the treatment of single-ventricle lesions with a systemic right ventricle.

\section{Limitations}

Limitations of our study are characterized by the retrospective design and the relatively small number of patients in the non-HLHS group. All comparisons are made on the basis of observational, nonrandomized data.

\section{CONCLUSIONS}

Our single-center experience shows that in the current era, the Norwood operation can be performed for complex single-ventricle lesions with similarly good short- and long-term outcomes regardless of the underlying anatomy. These results are encouraging for the treatment of singleventricle lesions with a systemic right ventricle. The higher incidence of recurrent aortic arch obstruction in the nonHLHS group can be explained by the presence of additional 
proximal aortic arch obstruction, which was not found in the HLHS group.

\section{References}

1. Mahle WT, Spray TL, Wernovsky G, Gaynor JW, Clark BJ III. Survival after reconstructive surgery for hypoplastic left heart syndrome: a 15-year experience from a single institution. Circulation. 2000;102(19 Suppl 3):III136-41.

2. Tweddell JS, Hoffman GM, Mussatto KA, Fedderly RT, Berger S, Jaquiss RD, et al. Improved survival of patients undergoing palliation of hypoplastic left heart syndrome: lessons learned from 115 consecutive patients. Circulation. 2002; 106(12 Suppl 1):I82-9.

3. McGuirk SP, Griselli M, Stumper OF, Rumball EM, Miller P, Dhillon R, et al. Staged surgical management of hypoplastic left heart syndrome: a single institution 12 year experience. Heart. 2006;92:364-70.

4. Azakie T, Merklinger SL, McCrindle BW, Van Arsdell GS, Lee KJ, Benson LN, et al. Evolving strategies and improving outcomes of the modified Norwood procedure: a 10-year single-institution experience. Ann Thorac Surg. 2001;72: 1349-53.

5. Furck AK, Uebing A, Hansen JH, Scheewe J, Jung O, Fischer G, et al. Outcome of the Norwood operation in patients with hypoplastic left heart syndrome: a 12-year single-center survey. J Thorac Cardiovasc Surg. 2010; 139:359-65

6. Furck AK, Hansen JH, Uebing A, Scheewe J, Jung O, Kramer HH. The impact of afterload reduction on the early postoperative course after the Norwood operation-a 12-year single-centre experience. Eur J Cardiothorac Surg. 2010;37: 289-95.

7. Jacobs ML, Rychik J, Murphy JD, Nicolson SC, Steven JM, Norwood WI. Results of Norwood's operation for lesions other than hypoplastic left heart syndrome. J Thorac Cardiovasc Surg. 1995;110:1555-61.

8. Jacobs JP, O'Brien SM, Chai PJ, Morell VO, Lindberg HL, Quintessenza JA. Management of 239 patients with hypoplastic left heart syndrome and related malformations from 1993 to 2007. Ann Thorac Surg. 2008;85:1691-6.

9. Daebritz SH, Nollert GD, Zurakowski D, Khalil PN, Lang P, del Nido PJ, et al. Results of Norwood stage I operation: comparison of hypoplastic left heart syndrome with other malformations. J Thorac Cardiovasc Surg. 2000;119: 358-67.

10. Mosca RS, Hennein HA, Kulik TJ, Crowley DC, Michelfelder EC, Ludomirsky A, et al. Modified Norwood operation for single left ventricle and ventriculoarterial discordance: an improved surgical technique. Ann Thorac Surg. 1997;64:1126-32.
11. Tchervenkov CI, Jacobs JP, Weinberg PM, Aiello VD, Béland MJ, Colan SD, et al. The nomenclature, definition and classification of hypoplastic left heart syndrome. Cardiol Young. 2006;16:339-68.

12. Bove EL. Current status of staged reconstruction for hypoplastic left heart syndrome. Pediatr Cardiol. 1998;19:308-15.

13. Fraser CD Jr. Management of systemic outlet obstruction in patients undergoing single ventricle palliation. Semin Thorac Cardiovasc Surg Pediatr Card Surg Аnпи. 2009;70-5.

14. Serraf A, Conte S, Lacour-Gayet F, Bruniaux J, Sousa-Uva M, Roussin R, et al. Systemic obstruction in univentricular hearts: surgical options for neonates. Ann Thorac Surg. 1995;60:970-6.

15. Thistlewaite PA, Myers JL, Siewers RD, Ettedgui JA. Technique for repair of single-ventricle hearts with transposition of the great arteries and aortic arch hypoplasia. Ann Thorac Surg. 1999;67:260-2.

16. Gaynor JW, Mahle WT, Cohen MI, Ittenbach RF, DeCampli WM, Steven JM, et al. Risk factors for mortality after the Norwood procedure. Eur J Cardiothorac Surg. 2002;22:82-9.

17. Zeltser I, Menteer J, Gaynor JW, Spray TL, Clark BJ, Kreutzer J, Rome JJ. Impact of re-coarctation following the Norwood operation on survival in the balloon angioplasty era. J Am Coll Cardiol. 2005;45:1844-8.

18. Tworetzky W, McElhinney DB, Burch GH, Teitel DF, Moore P. Balloon arterioplasty of recurrent coarctation after the modified Norwood procedure in infants. Catheter Cardiovasc Interv. 2000;50:54-8.

19. Bautista-Hernandez V, Marx GR, Gauvreau K, Pigula FA, Bacha EA, Mayer JE Jr, et al. Coarctectomy reduces neoaortic arch obstruction in hypoplastic left heart syndrome. J Thorac Cardiovasc Surg. 2007;133:1540-6.

20. Lotto AA, Hosein R, Jones TJ, Barron DJ, Brawn WJ. Outcome of the Norwood procedure in the setting of transposition of the great arteries and functional single left ventricle. Eur J Cardiothorac Surg. 2009;35:149-55.

21. Pearl JM, Cripe LW, Manning PB. Biventricular repair after Norwood palliation. Ann Thorac Surg. 2003;75:132-6.

22. Gruber PJ, Fuller S, Cleaver KM, Abdullah I, Gruber SB, Nicolson SC, et al. Early results of single-stage biventricular repair of severe aortic hypoplasia or atresia with ventricular septal defect and normal left ventricle. J Thorac Cardiovasc Surg. 2006;132:260-3.

23. Hirsch JC, Goldberg C, Bove EL, Salehian S, Lee T, Ohye RG, et al. Fontan operation in the current era: a 15-year single institution experience. Ann Surg. 2008; 248:402-10.

24. Tweddell JS, Nersesian M, Mussatto KA, Nugent M, Simpson P, Mitchell ME, et al. Fontan palliation in the modern era: factors impacting mortality and morbidity. Ann Thorac Surg. 2009;88:1291-9. 